\title{
Genetic basis of rifampicin resistance in methicillin-resistant Staphylococcus aureus suggests clonal expansion in hospitals in Cape Town, South Africa
}

Melissa J Jansen van Rensburg ${ }^{1,4}$, Andrew C Whitelaw ${ }^{1,2,3}$ and Brenda G Elisha ${ }^{1,2,3^{*}}$

\begin{abstract}
Background: Since 2001, several studies have reported high rifampicin resistance rates (45-100\%) among methicillin-resistant Staphylococcus aureus (MRSA) isolates from South Africa. The authors previously characterised 100 MRSA isolates from hospitals in Cape Town, South Africa; forty-five percent of these isolates were rifampicinresistant. The majority (44/45) corresponded to ST612-MRSA-IV, which is prevalent in South Africa, but has not been reported frequently elsewhere. The remaining rifampicin-resistant isolate corresponded to ST5-MRSA-I. The aim of this study was to investigate further the prevalence and genetic basis of rifampicin-resistance in MRSA isolates from hospitals in Cape Town.

Results: Between July 2007 and June 2011, the prevalence of rifampicin-resistant MRSA in hospitals in Cape Town ranged from $39.7 \%$ to $46.4 \%$. Based on the results of the aforementioned study, nine ST612-MRSA-IV isolates, the rifampicin-resistant ST5-MRSA-I isolate, and two rifampicin-susceptible MRSA isolates were investigated. Four previously described ST612-MRSA-IV isolates, including two each from South Africa and Australia, were also included.

The ST5-MRSA-I isolate carried a single mutational change, $\mathrm{H}_{481} \mathrm{Y}$, commonly associated with high-level rifampicin resistance. All ST612-MRSA-IV isolates carried an uncommon double amino acid substitution in RpoB, $\mathrm{H}_{481} \mathrm{~N}_{1} \mathrm{I}_{527} \mathrm{M}$, whilst one of the Australian ST612-MRSA-IV isolates carried an additional mutation within rpoB, representing a novel rpoB genotype: $\mathrm{H}_{481} \mathrm{~N}, \mathrm{I}_{527} \mathrm{M}, \mathrm{K}_{579} \mathrm{R}$. All ST612-MRSA-IV isolates also shared a unique silent single nucleotide polymorphism (SNP) within rpoB.

Conclusions: That local ST612-MRSA-IV isolates described here share an uncommon rpoB genotype and a unique silent SNP suggests this clone may have undergone clonal expansion in hospitals in Cape Town. Further, the data suggest that these isolates may be related to rifampicin-resistant ST612-MRSA-IV previously described in South Africa and Australia.
\end{abstract}

\section{Background}

It has long been acknowledged that antimicrobial use drives the emergence of resistant pathogens [1]. Currently in South Africa, rifampicin is used primarily for the treatment of tuberculosis, although it is also sometimes used in combination therapies to treat Staphylococcus aureus infections. A national antimicrobial

\footnotetext{
* Correspondence: gay.elisha@uct.ac.za

'Division of Medical Microbiology, Faculty of Health Sciences, University of Cape Town, Anzio Road, Observatory, Cape Town 7925, South Africa

Full list of author information is available at the end of the article
}

susceptibility surveillance study carried out in South Africa between 2005 and 2006 showed that $52.8 \%$ of MRSA isolates from public diagnostic laboratories were rifampicin-resistant [2]. Regional studies carried out between 2001 and 2006 in public hospitals in the KwaZulu Natal and Gauteng provinces of South Africa reported that $63-100 \%$ of MRSA isolates were rifampicin-resistant $[3,4]$. Given South Africa's high incidence of tuberculosis and subsequent widespread use of rifampicin, it is likely that selective pressure has propelled the
C Biomed Central

(c) 2012 Jansen van Rensburg et al; licensee BioMed Central Ltd. This is an Open Access article distributed under the terms of the Creative Commons Attribution License (http://creativecommons.org/licenses/by/2.0), which permits unrestricted use, distribution, and reproduction in any medium, provided the original work is properly cited. 
emergence and preponderance of rifampicin-resistant MRSA in this country.

A recent study on the molecular characterisation of MRSA from hospitals in Cape Town, South Africa, showed that ST612-MRSA-IV, a previously infrequently reported clone, was dominant in Cape Town hospitals [5]. Of the 100 MRSA isolates included in that study, 45 were rifampicin-resistant. Moreover, ST612-MRSAIVaccounted for 44 of these rifampicin-resistant isolates. The remaining rifampicin-resistant MRSA isolate corresponded to ST5-MRSA-I. A recent national report on MRSA clones circulating in South Africa indicated that ST612-MRSA-IV was the most prevalent and widespread clone [6]. However, whether these MRSA isolates were resistant to rifampicin was not reported. Prior to the Cape Town study [5] and the recently reported national investigation [6], only four clinical ST612MRSA-IV isolates had been described, including two each from South Africa and Australia, although the antimicrobial susceptibility profiles of these isolates were not reported [7-9].

Rifampicin is a bactericidal antimicrobial agent that inhibits transcription by binding to the $\beta$-subunit of the bacterial DNA-dependent RNA polymerase [10]. The $\beta$ subunit of RNA polymerase is encoded by $r p o B$, and mutations within conserved regions of the gene have been shown to confer resistance to rifampicin in a number of bacteria, including S. aureus [10-12]. The majority of mutations associated with rifampicin resistance in $S$. aureus have been mapped to a conserved region of rpoB known as the rifampicin resistance-determining region (RRDR) [11-13].

The available information on rifampicin resistance genotypes in $S$. aureus is restricted to a limited number of studies [11-17], which, to the best of our knowledge, have included only one isolate from South Africa [17]. This communication describes the prevalence and genetic basis of rifampicin resistance in MRSA from hospitals in Cape Town.

\section{Methods}

\section{Setting and statistical analysis of laboratory data}

The National Health Laboratory Service (NHLS) microbiology laboratory at Groote Schuur Hospital, Cape Town, serves three tertiary- and two secondary-level public hospitals situated within Cape Town. The laboratory data for all $S$. aureus isolates collected between July 2007 and June 2011 were retrieved from the NHLS database. The isolates were stratified according to methicillin and rifampicin susceptibilities. Differences between proportions were analysed using the $\chi^{2}$-test, and the $\chi^{2}$-test for trend was used to assess linear trends over time [18].

\section{Isolate selection}

$S$. aureus isolates were identified either by the production of DNAse, or on the VITEK 2 (bioMérieux, La Balme-les-Grottes, France). The authors recently used a combination of antimicrobial susceptibility testing, pulsed-field gel electrophoresis (PFGE), SCCmec typing, spa typing and multilocus sequence typing (MLST) to characterise 100 MRSA isolates obtained from hospitals in Cape Town between January 2007 and December 2008 [5]. The majority of the isolates were obtained from two tertiary level facilities, Groote Schuur Hospital (GSH) and Red Cross War Memorial Children's Hospital $(\mathrm{RCCH})$. Forty-five of the 100 isolates were rifampicin-resistant (44. ST612-MRSA-IV and 1 ST5-MRSA-I) [5].

Twelve of the previously characterised MRSA isolates described above were selected for $r p o B$ genotyping, and their properties are shown in Table 1. Two ST612MRSA-IV isolates, one each from GSH and RCCH, were selected from PFGE cluster D [5]. Both had spa type t064, the only type detected in representative isolates from this cluster [5]. Five ST612 MRSA-IV isolates, from four of the five hospitals (Table 1), were selected from the more genetically diverse PFGE cluster E [5]. Three spa types were identified in representative isolates from cluster E, with $\mathrm{t} 1443$ most frequently detected. Two of four sporadic ST612-MRSA-IV isolates were included. These isolates were obtained from GSH and $\mathrm{RCCH}$, with one corresponding to spa type $\mathrm{t} 1257$, which was not identified in any of the other ST612MRSA-IV isolates (Table 1) [5]. Also included were the rifampicin-resistant ST5-MRSA-I and two rifampicinsusceptible isolates (Table 1). Additionally, two ST612MRSA-IV from both South Africa (N83 and N84) [8] and Australia (04-17052 and 09-15534) [9] were included in the investigations (Table 1).

\section{Antimicrobial susceptibility testing}

The rifampicin and vancomycin MICs of the study isolates were determined by E-test (bioMérieux, La Balmeles-Grottes, France).

\section{rpoB genotyping}

A 702 bp region of rpoB spanning amino acid residues 441 to 673 ( $S$. aureus co-ordinates), including the RRDR, was amplified by PCR using primers designed by Aubry-Damon et al. [11]. The PCR was carried out in a final volume of $100 \mu \mathrm{l}$ with $1 \mathrm{X}$ reaction buffer, $1.5 \mathrm{mM}$ $\mathrm{MgCl}_{2}, 40$ pmol of each primer and $400 \mu \mathrm{M}$ of deoxynucleotide triphosphates (Thermo Scientific, Wilmington, DE, USA). One hundred nanograms of template DNA and $1 \mathrm{U}$ of Super Therm Taq DNA polymerase (JMR Holdings, London, UK) were added to each reac- 
Table 1 Characteristics of MRSA isolates selected for rpoB genotyping

\begin{tabular}{|c|c|c|c|c|c|c|}
\hline $\begin{array}{l}\text { Clonal type }{ }^{1} \text { (isolate } \\
\text { name) }\end{array}$ & $\begin{array}{l}\text { PFGE cluster }{ }^{2} \\
\text { (n) }\end{array}$ & $\begin{array}{l}\text { spa } \\
\text { type }\end{array}$ & $\begin{array}{l}\text { Rifampicin } \\
\text { phenotype }\end{array}$ & $\begin{array}{l}\text { Geographical } \\
\text { origin }\end{array}$ & $\begin{array}{l}\text { Hospital }^{4}(n) / \text { Year of } \\
\text { isolation }\end{array}$ & Reference \\
\hline ST612-MRSA-IV & $\mathrm{D}(2)$ & t064 & Resistant & Cape Town, RSA ${ }^{5}$ & GSH (1), RCCH (1)/2008 & [5] \\
\hline ST612-MRSA-IV & $E(1)$ & t064 & Resistant & Cape Town, RSA & UCTPH/2008 & {$[5]$} \\
\hline ST612-MRSA-IV & $E(4)$ & t1443 & Resistant & Cape Town, RSA & $\begin{array}{l}\mathrm{GSH}(2), \mathrm{RCCH}(1), \mathrm{VH}(1) / \\
2008\end{array}$ & [5] \\
\hline ST612-MRSA-IV & $\begin{array}{l}\text { Sporadic isolate } \\
\text { (1) }\end{array}$ & t1443 & Resistant & Cape Town, RSA & GSH/2008 & [5] \\
\hline ST612-MRSA-IV & $\begin{array}{l}\text { Sporadic isolate } \\
\text { (1) }\end{array}$ & $\mathrm{t} 1257$ & Resistant & Cape Town, RSA & $\mathrm{RCCH} / 2008$ & {$[5]$} \\
\hline ST5-MRSA-I & $C(1)$ & t045 & Resistant & Cape Town, RSA & $\mathrm{MMH} / 2008$ & [5] \\
\hline ST22-MRSA-IV & $\begin{array}{l}\text { Sporadic isolate } \\
\text { (1) }\end{array}$ & t032 & Susceptible & Cape Town, RSA & GSH/2008 & [5] \\
\hline ST36-MRSA-II & $F(1)$ & t021 & Susceptible & Cape Town, RSA & GSH/2007 & {$[5]$} \\
\hline ST612-MRSA-IV (N83, N84) & $N D^{6}(2)$ & t064 & Resistant & RSA & Unknown/2004 - 2005 & {$[8]$} \\
\hline ST612-MRSA-IV (04-17052) & ND (1) & t064 & Resistant & Perth, Australia & Unknown/2004 & [9] \\
\hline ST612-MRSA-IV (09-15534) & ND (1) & $\mathrm{t} 7571$ & Resistant & Perth, Australia & Unknown/2009 & [9] \\
\hline \multicolumn{7}{|c|}{$\begin{array}{l}{ }^{1} \text { Clonal types are indicated using the current international nomenclature (sequence type (ST) -antimicrobial phenotype - staphylococcal cassette chromosome } \\
\text { mec (SCCmec) type) }\end{array}$} \\
\hline \multicolumn{7}{|c|}{2 PFGE, pulsed-field gel electrophoresis } \\
\hline \multicolumn{7}{|c|}{${ }^{3}$ As determined by disc diffusion or on the VITEK 2} \\
\hline \multicolumn{7}{|c|}{$\begin{array}{l}{ }^{4} \text { GSH, Groote Schuur Hospital; RCCH, Red Cross War Memorial Children's Hospital; UCTPH, University of Cape Town Private Academic Hospital; VH, Victoria } \\
\text { Hospital; MMH, Mowbray Maternity Hospital }\end{array}$} \\
\hline \multicolumn{7}{|c|}{${ }^{5}$ RSA, Republic of South Africa } \\
\hline${ }^{6} \mathrm{ND}$, not determined & & & & & & \\
\hline
\end{tabular}

tion. Amplification was carried out using an Applied Biosystems 2720 Thermocycler (Applied Biosystems, Carlsbad, CA, USA). The PCR cycling conditions consisted of an initial denaturation step at $94^{\circ} \mathrm{C}$ for $4 \mathrm{~min}$, followed by 35 cycles of denaturation at $94^{\circ} \mathrm{C}$ for $30 \mathrm{~s}$, annealing at $52^{\circ} \mathrm{C}$ for $45 \mathrm{~s}$, elongation at $72^{\circ} \mathrm{C}$ for $45 \mathrm{~s}$, with a final extension step at $72^{\circ} \mathrm{C}$ for $3 \mathrm{~min}$.

The 702 bp fragment was purified using the MinElute Gel Extraction Kit (QIAGEN, Valencia, CA, USA), and both strands were sequenced directly at the Central Analytical Facility at the University of Stellenbosch. The nucleotide sequences obtained were aligned to the $r р о B$ sequence of rifampicin-susceptible $S$. aureus strain RN4220 (GenBank accession number: X64172) using the ClustalW algorithm in BioEdit Sequence Alignment Editor (version 7.0.5.2) [19].

\section{Results}

\section{Antimicrobial susceptibility testing}

The 14 rifampicin-resistant isolates expressed high-level rifampicin resistance (rifampicin MICs $\geq 256 \mathrm{mg} / \mathrm{L}$ ). The remaining 2 isolates were confirmed to be rifampicin-susceptible by E-test (rifampicin MICs $\leq 0.016 \mathrm{mg}$ / $\mathrm{L})$, as was previously determined by disc diffusion or on the VITEK 2 [5]. All 16 isolates were susceptible to vancomycin; 15 had vancomycin MICs $\leq 1 \mathrm{mg} / \mathrm{L}$ and one isolate, CT-C31-08 (ST5-MRSA-I), had a vancomycin $\mathrm{MIC}$ of $2 \mathrm{mg} / \mathrm{L}$.

\section{Prevalence of rifampicin resistance among $S$. aureus} isolates from hospitals in Cape Town

The NHLS microbiology laboratory at Groote Schuur Hospital carried out antimicrobial susceptibility testing on 13746 clinical S. aureus isolates between July 2007 and June 2011. MRSA accounted for 3298 (24\%) of all S. aureus isolates. Overall, 328 (3.1\%) of the methicillinsusceptible $S$. aureus (MSSA) isolates were resistant to rifampicin, while $1432(43.4 \%)$ of the MRSA isolates were rifampicin-resistant $(p<0.0001)$. No significant difference was detected in the prevalence of rifampicin resistance among MRSA isolates over the four year period $(p=0.0521)$, as illustrated in Figure 1 .

\section{Identification of mutations in $r p o B$}

The rpoB genotypes (GenBank accession numbers JN593081 - JN593085) and other molecular characteristics of the 16 isolates included in this investigation are shown in Table 2. No amino acid substitutions were observed in the RpoB protein sequences of the rifampicin-susceptible isolates. The ST5-MRSA-I isolate carried a single $\mathrm{H}_{481} \mathrm{Y}$ substitution known to confer high-level rifampicin resistance [11,12] (Table 2). The nine ST612MRSA-IV isolates from hospitals in Cape Town all carried the same double mutational changes within the RRDR, $\mathrm{H}_{481} \mathrm{~N}, \mathrm{I}_{527} \mathrm{M}$, which have also previously been associated with high-level rifampicin resistance in $S$. aureus [12,17]. N83 and N84, the ST612-MRSA-IV 


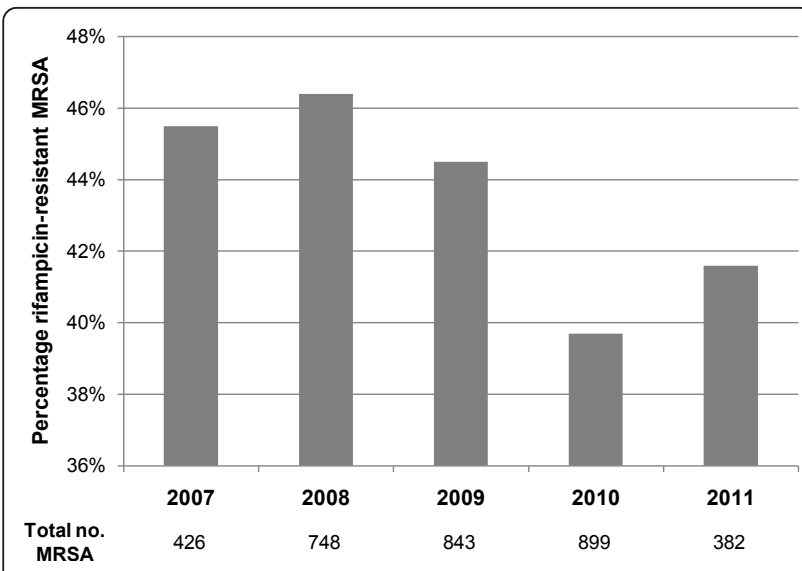

Figure 1 Annual percentage of rifampicin-resistant MRSA isolates collected between July 2007 and June 2011. Figures shown below the graph indicate the total number of MRSA isolates obtained each year, or part thereof. No significant difference was detected in the prevalence of rifampicin resistance among MRSA isolates over the four year period ( $p=0.0521$ ).

isolates previously identified in South Africa, also carried these changes. Similarly, the $\mathrm{H}_{481} \mathrm{~N}, \mathrm{I}_{527} \mathrm{M}$ double substitution was observed in 04-17052 and 09-15534, the two ST612-MRSA-IV isolates from Australia; however, an additional novel amino acid substitution, $\mathrm{K}_{579} \mathrm{R}$, was observed outside the RRDR in isolate 09-15534 (Table 2).

In addition to the mutations associated with amino acid substitutions in RpoB, silent single nucleotide polymorphisms (SNPs) were detected in the rpoB sequences of all 16 isolates (Table 2). Based on a comparison with the corresponding sequence of the rifampicin-susceptible $S$. aureus strain RN4220, all isolates shared a common SNP at amino acid 498 (GCG $\rightarrow$ GCT $)$, as shown in Table 2. Otherwise between one and three additional SNPs particular to each clonal type were identified. Of note is the conserved SNP at amino acid 512 (CGT $\rightarrow$ CGC), which was detected in all 13 ST612-MRSA-IV isolates (Table 2).

\section{Discussion}

A number of factors drive the emergence and spread of antibiotic resistance, including antibiotic usage, infection control practices and the organism's genetics [1]. Previous studies carried out in South Africa have reported large proportions of rifampicin-resistant MRSA isolates [2-5], and this study is no exception with the prevalence of rifampicin-resistance among MRSA isolates ranging from $39.7 \%$ to $46.4 \%$ (Figure 1 ). It is likely that the frequent use of rifampicin to treat tuberculosis in South Africa has driven the high prevalence of rifampicinresistance among local MRSA. Support for this suggestion comes from the work of Sekiguchi et al. [14] who reported a significantly higher prevalence of rifampicinresistant MRSA in tuberculosis wards compared to nontuberculosis wards in two hospitals in Japan.

A previous study showed that ST612-MRSA-IV was the dominant clone circulating in public hospitals in Cape Town. The 44 isolates corresponding to this clonal type were uniformly resistant to rifampicin. Only one other isolate of the $100 \mathrm{MRSA}$ investigated was resistant to this antibiotic and corresponded to ST5-MRSA-I [5]. Analysis of the RRDR of 14 rifampicin-resistant MRSA (rifampicin MICs $\geq 256 \mathrm{mg} / \mathrm{L}$ ), including the ST5MRSA-I isolate, nine representatives of Cape Town ST612-MRSA-IV isolates and four previously described ST612-MRSA-IV isolates, identified three rpoB genotypes; no amino acid substitutions were detected in the two rifampicin-susceptible isolates (rifampicin MICs $\leq$ $0.016 \mathrm{mg} / \mathrm{L}$ ) (Table 2).

The high-level rifampicin-resistant ST5-MRSA-I isolate carried a single mutational change within RpoB, $\mathrm{H}_{481} \mathrm{Y}$. This substitution, previously associated with high-level resistance, is one of the most common rifampicin resistance genotypes and has been reported previously in several laboratory mutants and clinical isolates [11-13,16,17]. Molecular modelling has demonstrated that the $\mathrm{H}_{481} \mathrm{Y}$ substitution disrupts an $\mathrm{H}$ bond between rifampicin and RNA polymerase, and also reduces hydrophobic interactions within the binding cavity, thereby decreasing the affinity of the drug for its target [13].

A relatively uncommon genotype, $\mathrm{H}_{481} \mathrm{~N}, \mathrm{I}_{527} \mathrm{M}$, previously reported in two clinical rifampicin-resistant MRSA from Italy [12] and a single vancomycin intermediate S. aureus (VISA) isolate from Brazil [17], accounted for 12 of the 13 high-level rifampicin-resistant ST612-MRSA-IV isolates, including N83, N84 and 04-17052. These results differ from the findings of Mick et al. [15] who detected four markedly different rifampicin resistance genotypes among 32 ST228-MRSA-IV isolates, expressing various levels of resistance, which were collected from a single hospital over three years.

The third rpoB genotype, $\mathrm{H}_{481} \mathrm{~N}, \mathrm{I}_{527} \mathrm{M}, \mathrm{K}_{579} \mathrm{R}$, was present in 09-15534, the remaining Australian ST612MRSA-IV isolate. To the best of our knowledge, $K_{579} R$, which occurs outside the RRDR, has not been reported previously, hence $\mathrm{H}_{481} \mathrm{~N}, \mathrm{I}_{527} \mathrm{M}, \mathrm{K}_{579} \mathrm{R}$ represents a novel rpoB genotype. Whether the latter substitution impacts rifampicin resistance is unknown because the RRDR of this isolate contains two other mutations associated with resistance to this antibiotic. It is possible that this novel $K_{579} R$ substitution represents the latest mutational change in ST612-MRSA-IV as isolate 0915534 was isolated in 2009, whereas the other MRSA strains included in this study were collected between 2004 and 2008. 
Table 2 Results of rifampicin susceptibility testing and rpoB genotyping

\begin{tabular}{|c|c|c|c|c|c|c|}
\hline $\begin{array}{c}\text { Clonal type }{ }^{1} \\
\text { (clonal complex) }\end{array}$ & PFGE cluster $^{2}(\mathrm{n}) /$ spa type $(\mathrm{n})$ & $\begin{array}{c}\text { Isolate origin } \\
\text { (isolate name) }\end{array}$ & $\begin{array}{c}\text { Rifampicin } \\
\text { MIC (mg/L) }\end{array}$ & $\begin{array}{l}\text { Amino acid } \\
\text { position }^{4}\end{array}$ & $\begin{array}{c}\text { Nucleotide } \\
\text { substitution }\end{array}$ & $\begin{array}{l}\text { Amino acid } \\
\text { substitution }\end{array}$ \\
\hline \multirow[t]{3}{*}{ ST22- MRSA-IV (22) } & Sporadic isolate (1)/t032 (1) & Cape Town, RSA ${ }^{5}$ & $\leq 0.016$ & 498 & $\mathrm{GCG} \rightarrow \mathrm{GCT}$ & - \\
\hline & & & & 554 & $\mathrm{CAT} \rightarrow \mathrm{CAC}$ & - \\
\hline & & & & 599 & $\mathrm{AAT} \rightarrow \mathrm{AAC}$ & - \\
\hline \multirow[t]{4}{*}{ ST36- MRSA-II (30) } & $F(1) / t 021(1)$ & Cape Town, RSA & $\leq 0.016$ & 474 & $\mathrm{AAC} \rightarrow \mathrm{AAI}$ & - \\
\hline & & & & 498 & $\mathrm{GCG} \rightarrow \mathrm{GCI}$ & - \\
\hline & & & & 502 & $\mathrm{GTA} \rightarrow \mathrm{GTG}$ & - \\
\hline & & & & 518 & $\mathrm{ACA} \rightarrow \mathrm{ACG}$ & - \\
\hline \multirow[t]{4}{*}{ ST5- MRSA-I (5) } & $C(1) / \mathrm{t} 045(1)$ & Cape Town, RSA & $\geq 256$ & 481 & $\underline{\mathrm{CAT}} \rightarrow \underline{\mathrm{TAT}}$ & $\mathrm{H}_{481} \mathrm{Y}$ \\
\hline & & & & 498 & $\mathrm{GCG} \rightarrow \mathrm{GCI}$ & - \\
\hline & & & & 630 & $\mathrm{AAT} \rightarrow \mathrm{AAC}$ & - \\
\hline & & & & 658 & $\mathrm{GGT} \rightarrow \mathrm{GGA}$ & - \\
\hline \multirow[t]{4}{*}{ ST612- MRSA-IV (8) } & $\begin{array}{c}\mathrm{D}(2), \mathrm{E} \mathrm{(5),} \mathrm{sporadic} \mathrm{isolates} \mathrm{(2)/t064} \\
\text { (3), t1443 (5), t1257 (1) }\end{array}$ & Cape Town, RSA & $\geq 256$ & 481 & $\underline{\mathrm{CAT}} \rightarrow \underline{\mathrm{AAT}}$ & $\mathrm{H}_{481} \mathrm{~N}$ \\
\hline & & & & 498 & $\mathrm{GCG} \rightarrow \mathrm{GCI}$ & - \\
\hline & & & & 512 & $\mathrm{CGT} \rightarrow \mathrm{CG} \underline{C}$ & - \\
\hline & & & & 527 & $\mathrm{ATT} \rightarrow \mathrm{ATG}$ & $\mathrm{I}_{527} \mathrm{M}$ \\
\hline \multirow[t]{4}{*}{ ST612- MRSA-IV (8) } & $\mathrm{ND}^{6}(2) / \mathrm{t} 064(2)$ & RSA (N83; N84) & $\geq 256$ & 481 & $\underline{\mathrm{CAT}} \rightarrow \underline{\mathrm{AAT}}$ & $\mathrm{H}_{481} \mathrm{~N}$ \\
\hline & & & & 498 & $\overline{\mathrm{GCG}} \rightarrow \overline{\mathrm{GCT}}$ & - \\
\hline & & & & 512 & $\mathrm{CGT} \rightarrow \mathrm{CG} \underline{C}$ & - \\
\hline & & & & 527 & $\mathrm{ATI} \rightarrow \mathrm{ATG}$ & $\mathrm{I}_{527} \mathrm{M}$ \\
\hline \multirow[t]{4}{*}{ ST612- MRSA-IV (8) } & ND (1)/t064 (1) & $\begin{array}{l}\text { Australia (04- } \\
\text { 17052) }\end{array}$ & $\geq 256$ & 481 & $\underline{\mathrm{CAT}} \rightarrow \underline{\mathrm{AAT}}$ & $\mathrm{H}_{481} \mathrm{~N}$ \\
\hline & & & & 498 & $\mathrm{GCG} \rightarrow \mathrm{GCI}$ & - \\
\hline & & & & 512 & $\mathrm{CGI} \rightarrow \mathrm{CG} \underline{C}$ & - \\
\hline & & & & 527 & $\mathrm{AT} \underline{-} \rightarrow \mathrm{ATG}$ & $\mathrm{I}_{527} \mathrm{M}$ \\
\hline \multirow[t]{5}{*}{ ST612- MRSA-IV (8) } & ND (1)/t7571 (1) & $\begin{array}{l}\text { Australia (09- } \\
\text { 15534) }\end{array}$ & $\geq 256$ & 481 & $\underline{\mathrm{CAT}} \rightarrow \underline{\mathrm{AAT}}$ & $\mathrm{H}_{481} \mathrm{~N}$ \\
\hline & & & & 498 & $\mathrm{GCG} \rightarrow \mathrm{GCI}$ & - \\
\hline & & & & 512 & $\mathrm{CGT} \rightarrow \mathrm{CG} \bar{C}$ & - \\
\hline & & & & 527 & $A T \underline{T} \rightarrow A T \underline{G}$ & $\mathrm{I}_{527} \mathrm{M}$ \\
\hline & & & & 579 & $\mathrm{AAA} \rightarrow \mathrm{AG} A$ & $\mathrm{~K}_{579} \mathrm{R}$ \\
\hline
\end{tabular}

${ }^{1}$ Clonal types are indicated using the current international nomenclature (sequence type (ST) - antimicrobial phenotype - staphylococcal cassette chromosome mec (SCCmec) type)

${ }^{2}$ PFGE, pulsed-field gel electrophoresis

${ }^{3}$ As determined by E-test

${ }^{4}$ S. aureus co-ordinates

${ }^{5}$ RSA, Republic of South Africa

${ }^{6} \mathrm{ND}$, not determined

A number of silent SNPs were detected in the 16 isolates when using the nucleotide sequence of RN4220 as a reference (Table 2). One SNP at amino acid position 498 (GCG $\rightarrow$ GCT) was common to all 16 isolates, which belonged to four different $S$. aureus clonal complexes (CCs) (Table 2). This SNP has also been reported in ST247-MRSA-I control strains ATCCBAA44 and PER88 (CC8), and in ST228-MRSA-I (CC5) isolates from Spain [15]. Codon usage tables derived from genome sequences of six $S$. aureus control strains (NCTC8325, COL, Newman, USA300, N315 and $\mathrm{Mu} 50$ ), indicated that the codon GCT is twice as prevalent as GCG [20]. It is possible that the SNP arose on separate occasions in multiple $S$. aureus lineages and that its prevalence is related to codon bias in this organism. However, it seems more likely that RN4220 contains the SNP (GCT $\rightarrow$ GCG), which arose once in this strain. This can only be confirmed when more rpoB sequences of $S$. aureus isolates from a variety of genetic backgrounds become available.

Of greater interest is the only other conserved silent SNP found in the codon for arginine at amino acid position 512 (CGT $\rightarrow$ CGC) that was observed in all ST612MRSA-IV isolates (Table 2). This mutation was notable for two reasons: firstly, AT-rich organisms such as $S$. aureus more commonly favour AT-rich codons with 
either adenine or thymine bases, rather than cytosine, at the third position [21,22]; secondly, codon usage tables indicated that CGT is more common than CGC for arginine [20]. Thus, it is possible to suggest that the SNP (CGT $\rightarrow$ CGㅡ) has not arisen on multiple occasions in ST612-MRSA-IV, but instead was inherited from a common ancestor and has been conserved within the lineage.

Interestingly, ST612-MRSA-IV has also recently been reported as the predominant clone in a population of horses in Australia [23]. All of the equine ST612MRSA-IV isolates that were tested were rifampicinresistant, making it tempting to speculate that they may be related to those described in this study; however, the equine strains carried SCCmec type IVa [23], while the ST612-MRSA-IV isolates from Cape Town and Australia carried SCCmec type lished data), which suggests at least two separate $\mathrm{SCCmec}$ acquisitions in this genetic background.

Although mutations associated with resistance frequently evince an initial fitness cost to the organism, it has been shown that rifampicin-resistant E. coli do not revert to wild-type susceptibility in the absence of this antibiotic. Rather, they persist because of their capacity to develop compensatory mutations, which restore bacterial fitness [24]. Other studies have also suggested that the reduction of antibiotic pressure may not necessarily result in reversion to susceptibility [25], which is worrying in our setting given that ST612-MRSA-IV is multidrug-resistant [5].

Vancomycin remains the drug of choice for the treatment of multidrug-resistant MRSA infections; however, the emergence of vancomycin-resistant $S$. aureus poses a new challenge. Watanabe et al. [17] have suggested that certain mutational changes in $r p o B$, including $\mathrm{H}_{481} \mathrm{Y}$, may be linked to reduced vancomycin susceptibility in S. aureus. In light of these facts, the vancomycin MICs of isolates selected for $r p o B$ genotyping in the current study were determined by E-test. Interestingly, the ST5-MRSA-I isolate, with $r p o B$ genotype $\mathrm{H}_{481} \mathrm{Y}$, was susceptible to vancomycin (MIC of $2 \mathrm{mg} / \mathrm{L}$ ). Of interest is the observation that isolates with MICs of $2 \mathrm{mg} / \mathrm{L}$ have been associated with a poor clinical response to vancomycin [26]. All ST612-MRSA-IV were susceptible to vancomycin (MICs of $\leq 1 \mathrm{mg} / \mathrm{L}$ ), suggesting that the mutational changes present in $r p o B$ in these isolates are not associated with resistance to vancomycin.

\section{Conclusions}

A subset of ST612-MRSA-IV isolates from Cape Town hospitals, broadly representative of the total collection with respect to molecular characteristics, as well as the hospital of isolation, was selected to determine the mechanism of rifampicin resistance in this clone.
Collectively, the data support a hypothesis of clonal expansion of a rifampicin-resistant ST612-MRSA-IV strain in local hospitals. The data also suggest that these isolates may be related to rifampicin-resistant ST612MRSA-IV previously described in South Africa and Australia. Studies including additional ST612-MRSA-IV isolates collected from South Africa, Australia and the United Kingdom are required to investigate further the evolution of this clone.

\section{Acknowledgements}

We are grateful to the Australian Collaborating Centre for Enterococcus and Staphylococcus Species Typing and Research for providing strains 04-17052 and 09-15534, and Professor Richard Goering for providing N83 and N84.

We would like to thank the staff of the National Health Laboratory Service microbiology laboratory at Groote Schuur Hospital for their contributions to this study, particularly Ms Shireen Grimwood for her assistance with antimicrobial susceptibility testing. We are also grateful to Darren Martin and Paul McAdam for helpful discussions regarding the manuscript.

This study was supported by grants from the University of Cape Town and the National Health Laboratory Service. MJJvR was supported by the University of Cape Town, the National Research Foundation and the Ernst and Ethel Eriksen Trust. Aspects of this work were presented at the $14^{\text {th }}$ International Symposium on Staphylococci and Staphylococcal Infections, 6 9 September 2010, Bath, England.

\section{Author details}

${ }^{1}$ Division of Medical Microbiology, Faculty of Health Sciences, University of Cape Town, Anzio Road, Observatory, Cape Town 7925, South Africa. ${ }^{2}$ National Health Laboratory Service, Groote Schuur Hospital, Anzio Road, Observatory, Cape Town 7925, South Africa. ${ }^{3}$ National Institute for Communicable Diseases, National Health Laboratory Service, University of Cape Town, Anzio Road, Observatory, Cape Town 7925, South Africa. ${ }^{4}$ Current address: Department of Zoology, University of Oxford, The Tinbergen Building, South Parks Road, Oxford OX1 3PS, UK.

\section{Authors' contributions}

MJJVR and BGE conceived and designed the study. MJJVR carried out the molecular studies. AW co-ordinated clinical aspects of the study. AW also obtained, analysed and interpreted the clinical data. MJJVR and BGE wrote the manuscript, which was critically reviewed by AW. All authors read and approved the final manuscript.

Received: 23 August 2011 Accepted: 26 March 2012

Published: 26 March 2012

\section{References}

1. Levy SB: The 2000 Garrod Lecture. Factors impacting on the problem of antibiotic resistance. J Antimicrob Chemoth 2002, 49:25-30.

2. Marais E, Aithma N, Perovic O, Oosthuysen WF, Musenge E, Dusé AG: Antimicrobial susceptibility of methicillin-resistant Staphylococcus aureus isolates from South Africa. SAMJ 2009, 99:170-173.

3. Shittu $A O$, Lin J: Antimicrobial susceptibility patterns and characterization of clinical isolates of Staphylococcus aureus in KwaZulu-Natal province, South Africa. BMC Infect Dis 2006, 6:125.

4. Groome MJ, Albrich W, Khoosal M, Wadula J, Madhi SA: Staphylococcus aureus bacteraemia on admission in paediatric patients at Chris Hani Baragwanath Hospital, Soweto. Abstracts: 3rd FIDSSA Congress, 2009: 20 23 August 2009; South Africa 2009, 26-27.

5. Jansen van Rensburg MJ, Madikane VE, Whitelaw A, Chachage M, Haffejee S, Elisha BG: The dominant methicillin-resistant Staphylococcus aureus clone from hospitals in Cape Town has an unusual genotype: ST612. Clin Microbiol Infect 2011, 17:785-792.

6. Moodley A, Oosthuysen WF, Dusé AG, Marais E, the South African MRSA Surveillance Group: Molecular characterization of clinical methicillinresistant Staphylococcus aureus in South Africa. J Clin Microbiol 2010, 48:4608-4611. 
7. The Multilocus Sequence Typing Network. [http://saureus.mlst.net/].

8. Goering RV, Shawar RM, Scangarella NE, O'Hara FP, Amrine-Madsen H, West JM, Dalessandro M, Becker JA, Walsh SL, Miller LA, van Horn SF, Thomas ES, Twynholm ME: Molecular epidemiology of methicillinresistant and methicillin-susceptible Staphylococcus aureus isolates from global clinical trials. J Clin Microbiol 2008, 46:2842-2847.

9. Coombs G, Monecke S, Pearson JC, Tan H, Chew Y, Wilson L, Ehricht R, O'Brien FG, Christiansen KJ: Evolution and diversity of communityassociated methicillin-resistant Staphylococcus aureus in a geographical region. BMC Microbiol 2011, 11:215.

10. Campbell EA, Korzheva N, Mustaev A, Murakami K, Nair S, Goldfarb A, Darst SA: Structural Mechanism for Rifampicin Inhibition of Bacterial RNA Polymerase. Cell 2001, 104:901-912.

11. Aubry-Damon H, Soussy CJ, Courvalin P: Characterization of mutations in the $r p o B$ gene that confer rifampin resistance in Staphylococcus aureus. Antimicrob Agents Chemother 1998, 42:2590-2594.

12. Wichelhaus TA, Schafer V, Brade V, Böddinghaus B: Molecular characterization of $r p o B$ mutations conferring cross-resistance to rifamycins on methicillin-resistant Staphylococcus aureus. Antimicrob Agents Chemother 1999, 43:2813-2816.

13. O'Neill AJ, Huovinen T, Fishwick CWG, Chopra I: Molecular genetic and structural modeling studies of Staphylococcus aureus RNA polymerase and the fitness of rifampin resistance genotypes in relation to clinical prevalence. Antimicrob Agents Chemother 2006, 50:298-309.

14. Sekiguchi J, Fujino T, Araake M, Toyota E, Kudo K, Saruta K, Yoshikura H, Kuratsuji T, Kirikae T: Emergence of rifampicin resistance in methicillinresistant Staphylococcus aureus in tuberculosis wards. I Infect Chemother 2006, 12:47-50.

15. Mick V, Domínguez MA, Tubau F, Liñares J, Pujol M, Martin R: Molecular characterization of resistance to rifampicin in an emerging hospitalassociated methicillin-resistant Staphylococcus aureus clone ST228, Spain. BMC Microbiol 2010, 10:68.

16. Villar M, Marimón JM, García-Arenzana JM, de la Campa AG, Ferrándiz MJ, Pérez-Trallero E: Epidemiological and molecular aspects of rifampicinresistant Staphylococcus aureus isolated from wounds, blood and respiratory samples. J Antimicrob Chemother 2011, 66:997-1000.

17. Watanabe Y, Cui L, Katayama Y, Kozue K, Hiramatsu K: Impact of rpoB mutations on reduced vancomycin susceptibility in Staphylococcus aureus. J Clin Microbiol 2011, 49:2680-2684.

18. VassarStats: Website for Statistical Computation. [http://vassarstats.net/].

19. Hall TA: BioEdit: a user-friendly biological sequence alignment editor and analysis program for Windows 95/98/NT. Nucl Acids Symp Ser 1999, 41:95-98.

20. Codon Usage Database. [http://www.kazusa.or.jp/codon/].

21. Ermolaeva MD: Synonymous codon usage in bacteria. Curr Issues Mol Biol 2001, 3:91-97.

22. Hershberg R, Petrov DA: General rules for optimal codon choice. PLoS Genet 2009, 5(7):e1000556.

23. Axon JE, Carrick JB, Barton MD, Collins NM, Russell CM, Kiehnea J, Coombs G: Methicillin-resistant Staphylococcus aureus in a population of horses in Australia. Aust Vet J 2011, 89:221-225.

24. Reynolds MG: Compensatory evolution in rifampin-resistant Escherichia coli. Genetics 2000, 156:1471-1481.

25. Andersson DI: The biological cost of mutational antibiotic resistance: any practical conclusions? Curr Opin Microbiol 2006, 9:461-465.

26. Soriano A, Marco F, Martínez JA, Pisos E, Almela M, Dimova VP, Alamo D, Ortega M, Lopez J, Mensa J: Influence of vancomycin minimum inhibitory concentration on the treatment of methicillin-resistant Staphylococcus aureus bacteremia. Clin Infect Dis 2008, 46:193-200.

doi:10.1186/1471-2180-12-46

Cite this article as: Jansen van Rensburg et al:: Genetic basis of rifampicin resistance in methicillin-resistant Staphylococcus aureus suggests clonal expansion in hospitals in Cape Town, South Africa. BMC Microbiology 2012 12:46.

\section{Submit your next manuscript to BioMed Central and take full advantage of:}

- Convenient online submission

- Thorough peer review

- No space constraints or color figure charges

- Immediate publication on acceptance

- Inclusion in PubMed, CAS, Scopus and Google Scholar

- Research which is freely available for redistribution 